\title{
Hormonal regulation of tight junction closure in the mouse mammary epithelium during the transition from pregnancy to lactation
}

\author{
D-A Nguyen, A F Parlow ${ }^{1}$ and M C Neville \\ Department of Physiology, University of Colorado School of Medicine, Denver, Colorado 80262, USA \\ ${ }^{1}$ National Hormone and Pituitary Program, Harbor-UCLA Medical Center Research and Education Institute, Torrance, California 90509, USA \\ (Requests for offprints should be addressed to M C Neville, Department of Physiology, Box C240, Room 3802, University of Colorado Health Sciences Center, \\ Denver, Colorado 80262, USA; Email: peggy.neville@uchsc.edu)
}

\begin{abstract}
Closure of the tight junctions of the mammary epithelium has been shown to accompany the onset of copious milk secretion or lactogenesis, stage 2 , in both goats and humans. Here we use injection of $\left[{ }^{14} \mathrm{C}\right]$ sucrose and FITC-albumin (fluorescein isothiocyanate-albumin) into the mammary duct to follow the course of tight junction closure during lactogenesis in mice. To examine the hormonal changes responsible, we ovariectomized day 16 or 17 pregnant mice and found that closure followed ovariectomy with a mean delay of $13.6 \pm 1.5$ (s.E.M.) h. That progesterone withdrawal is the trigger for closure was shown by the finding that injection of progesterone within $4 \mathrm{~h}$ of ovariectomy delayed closure and that closure
\end{abstract}

occurred after injection of the progesterone antagonist RU 486 in intact late pregnant mice. Endocrine ablation studies showed that low to moderate concentrations of corticosterone and either placental lactogen or prolactin are necessary for tight junction closure triggered by progesterone withdrawal. Thus the hormonal requirements for tight junction closure are similar to those shown by other investigators to promote lactogenesis, stage 2 . Further, the tight temporal control of tight junction permeability suggests that ovariectomy of the late pregnant mouse may be a good model for molecular studies of the lactogenic switch.

Journal of Endocrinology (2001) 170, 347-356

\section{Introduction}

Small amounts of a secretion product resembling colostrum can be extracted from the mammary glands of ruminants and humans prior to parturition. This fluid contains more protein, sodium and chloride and less lactose and potassium than true milk. The composition of the mammary secretion begins to change around parturition, the timing depending on the species, and gradually approaches the composition of true milk. Much of this change in composition can be attributed to closure of tight junctions (also called zonula occludins) between the mammary epithelial cells during the onset of copious milk secretion, technically called lactogenesis, stage 2 (Fleet et al. 1975, Neville 1995). As shown by experiments in which disaccharides were injected up the teats of goats, the mammary epithelium is highly permeable during pregnancy. Thus when Linzell \& Peaker (1974) injected $\left[{ }^{14} \mathrm{C}\right]$ sucrose into the lumen of the goat udder, they observed the immediate presence of the tracer within the bloodstream. Only a fraction of the tracer could be recovered in the milk. In contrast, during lactation no tracer could be observed in the bloodstream, and all injected tracer remained within the mammary gland until removed by milking. Similar results were obtained by Berga in the lactating mouse (Berga 1984). Linzell \& Peaker $(1971,1974)$ also showed that $\left[{ }^{14} \mathrm{C}\right]$ sucrose moved from the bloodstream into the mammary secretion of goats during pregnancy but not lactation; higher concentrations were observed in milk fractions derived from the alveoli than from the ducts, indicating that most of the leaky tight junctions are in the alveolar epithelium. At the same time Pitelka and her colleagues (1973) used freeze fracture analysis to show that the disorganized pattern of the tight junction strands in the mammary gland of pregnancy becomes highly organized in lactation. This observation provided a structural basis for the observed physiologic changes in epithelial permeability. Together findings from tracer, milk composition and cell biological experiments indicate that the mammary tight junctions, particularly in the alveoli, are leaky during pregnancy and close around parturition to form a tight barrier that prevents paracellular movement of molecules across the mammary epithelium.

The hormonal regulation of tight junction closure per se has not been studied. However, lactogenesis itself is thought to be triggered by progesterone withdrawal and to 
depend on the presence of glucocorticoids and prolactin (Neville et al. 2001). Progesterone is also the hormone that maintains pregnancy, and results from a number of studies indicate that its withdrawal around the time of parturition is the trigger that initiates milk secretion. Thus Kuhn (1969) demonstrated that ovariectomy, which removes the main source of progesterone in pregnant rodents, induces the synthesis of lactose in the mammary gland of late pregnant rats. Nishikawa et al. (1994) used ovariectomy to study the effect of progesterone withdrawal on the expression of prolactin receptors and the level of $\beta$-casein mRNA. Ovariectomy induced an increase in the level of $\beta$-casein mRNA that began between 3 and $8 \mathrm{~h}$ postovariectomy and reached a maximum of fourfold at $24 \mathrm{~h}$. Deis \& Delouis (1983) found that ovariectomy of day 19 pregnant mice increased the level of galactosyl transferase, an enzyme involved in lactose synthesis, at $24 \mathrm{~h}$ postovariectomy, as well as the level of $\alpha$-lactalbumin, another major milk protein, $6 \mathrm{~h}$ after ovariectomy. In all of these studies, the various aspects of lactogenesis induced by ovariectomy could be suppressed by exogenous progesterone, indicating that these effects of ovariectomy were progesterone specific.

On the basis of these experiments we hypothesized that progesterone withdrawal also triggers the closure of tight junctions in the mammary epithelium during stage 2 lactogenesis. To test this hypothesis, ovariectomy, which removes the main source of progesterone, was used to examine the effect of progesterone withdrawal on tight junction permeability in late pregnant mice. Tight junction permeability was monitored by injecting $\left[{ }^{14} \mathrm{C}\right]$ sucrose into the lumen of the mammary gland and measuring its leakage into the bloodstream. A number of experimental manipulations as well as injection of FITC-albumin (fluorescein isothiocyanate-albumin) were used to validate this technique. The results of these experiments support the hypothesis that progesterone withdrawal at the termination of pregnancy is the trigger for tight junction closure in the mammary gland. However, additional endocrine ablation experiments point to roles for glucocorticoids, prolactin and placental lactogen in this process.

\section{Materials and Methods}

\section{Animals}

CD-1 mice were purchased from Charles River Breeding Laboratory (Wilmington, MA, USA) and maintained in the USDA approved Animal Care Resource of the University of Colorado Health Sciences Center. Pregnancies were timed by observing a vaginal plug after overnight residence with a male. Day 16-17 pregnant and day 1 lactating mice were used. Inconsistent results were obtained later in pregnancy presumably because the parturition process begins about day 18 in this strain of mice maintained in Denver. Mice were maintained on Breeder chow and allowed to feed ad libitum, and were kept under a $12 \mathrm{~h}$ cycle of alternating artificial light and darkness. All mice were anesthetized with avertin and sacrificed by cervical dislocation at the end of each experiment. All procedures were approved by Internal Animal Care and Use Committee of the University of Colorado.

\section{Surgical and injection procedures}

The ovaries and adrenal glands were removed by dorsolateral laparotomy. The mice were fully anesthetized with avertin (2,2,2-tribromoethanol; $0.3 \mathrm{mg} / \mathrm{g}$ of body weight). All hair within $1 \mathrm{~cm}$ of the skin incision was shaved off and the area disinfected with betadine soap, isopropyl alcohol and iodine solution. A $1 \mathrm{~cm}$ incision was made in the skin at the mid-back followed by a $0.7 \mathrm{~cm}$ incision in the body wall over each kidney. Blood vessels supplying the ovaries and, when indicated, the adrenal glands were ligated and the organs were removed with surgical scissors. The incisions in the body wall and the skin were closed with surgical thread. For sham ovariectomy, the same surgical procedure was used except for the ligation of blood vessels and excision of the ovaries. For hysterectomy, the animal was anesthetized and the area of the incision was prepared as above. The uterus and all the fetuses contained within were removed from the body cavity through a $1.5 \mathrm{~cm}$ midline incision in the lower abdomen. The blood vessels supplying the uterus and its opening to the cervix were ligated with surgical thread below the two ovaries and at the cervix. The uterus was then removed with surgical scissors. Incisions in the skin and body wall were closed with surgical thread. Animals were allowed to recover on a heating pad and were closely observed until the effects of the anesthetic had worn off.

Injections were given under avertin anesthesia usually immediately following the surgical procedure. Progesterone (Sigma, St Louis, MO, USA) was dissolved in 90\% vegetable oil $/ 10 \%$ ethanol, and $0 \cdot 1 \mathrm{ml}$ of the solution was injected subcutaneously at a dose of $0.028 \mathrm{mg} / \mathrm{g}$ of body weight. RU486 (Roussel-UCLAF, Romainville, France) and bromocryptine (Sigma) were administered as $0.1 \mathrm{ml}$ subcutaneous injections at doses of 0.01 and $0.005 \mathrm{mg} / \mathrm{g}$ respectively in $90 \%$ saline $/ 10 \%$ ethanol. Dexamethasone (Sigma) was similarly administered at 0.005, 0.01 and $0.02 \mathrm{mg} / \mathrm{g}$ as needed.

\section{Tracer studies of mammary epithelial permeability}

Tracer injection was performed under avertin anesthesia. Two $\mu \mathrm{Ci}$ of $\left[{ }^{14} \mathrm{C}\right]$ sucrose (Amersham, Buckinghamshire, UK) was lyophilized and dissolved in $10 \mu \mathrm{l}$ of sterile Ringer Solution $\left(138 \mathrm{mM} \mathrm{NaCl}, 8.1 \mathrm{mM} \mathrm{Na} \mathrm{HPO}_{4}\right.$, $1.2 \mathrm{mM} \mathrm{K}_{2} \mathrm{HPO}_{4}, 2.7 \mathrm{mM} \mathrm{KH_{2 }} \mathrm{PO}_{4}, 0.9 \mathrm{mM} \mathrm{CaCl}_{2}$, $0.5 \mathrm{mM} \mathrm{MgCl}_{2}$ ). This solution was loaded into a Drummond microinjector, which had as the injection barrel a $1 \mathrm{~mm}$ glass capillary tube with its end flame drawn 
into a fine tip, 60-90 $\mu \mathrm{m}$ outside diameter, and heatpolished. The tip was inserted into the teat canal using a micromanipulator and the solution slowly ejected into the lumen of the mammary gland as described in Nguyen et al. (2000).

To visualize tight junction permeability the animal was anesthetized as above and $10 \mu \mathrm{l}$ of a solution containing $3 \mathrm{mg} / \mathrm{ml}$ FITC-albumin in PBS was injected intraductally into the lumen of the fourth mammary gland followed within $5 \mathrm{~min}$ by intraductal injection of $25 \mu \mathrm{l}$ of $10 \%$ paraformaldehyde to quickly immobilize the tracer. The animal was then perfusion-fixed with $30 \mathrm{ml}$ of $2 \cdot 5 \%$ paraformaldehyde injected into the left ventricle over $15 \mathrm{~min}$. After removal of the gland it was further fixed in $2.5 \%$ paraformaldehyde at $4{ }^{\circ} \mathrm{C}$, embedded in methacrylate (JB4 resin, Polyscience, Inc., Warrington, PA, USA), sectioned at $4 \mu \mathrm{m}$ and visualized with a Nikon fluorescent microscope equipped with a digital camera. Slidebook software (Intelligent Imaging Innovations, Denver, CO, USA) was used to capture the image. For quantitation of fluorescence intensity inside cells, images of the cell's interior were captured at identical magnification and exposure times and fluorescence intensity measured with Slidebook software. In a second variation of this experiment designed to expose the basolateral surfaces of the alveoli to fluorescent tracer, the fourth mammary gland was surgically exposed, the skin with this gland deflected and pinned to a dissection board to form a cup. Two milliliters of PBS containing $3 \mathrm{mg} / \mathrm{ml}$ FITC-albumin was placed over the gland and allowed to penetrate for $1 \mathrm{~h}$. The mouse was kept warm on a heating pad under deep anesthesia. Perfusion fixation, embedding, and visualization were carried out as for the intraductal injection.

\section{Determination of tight junction closure time in response to ovariectomy or other treatment}

For determining tight junction closure time in response to ovariectomy or other treatment, $\left[{ }^{14} \mathrm{C}\right]$ sucrose was injected intraductally into the lumen of the mammary glands immediately before and at intervals after surgery or treatment with RU486 to monitor tight junction permeability. Ten microliter blood samples were taken before and $5 \mathrm{~min}$ after each injection and counted for ${ }^{14} \mathrm{C}$ activity. The difference between the two samples was plotted as a function of time, usually normalized to the peak of the injection made prior to surgical manipulation. The data were fitted with a sigmoidal function using the equation,

$$
y=A+(1-A) /\left(1+\exp \left(a\left(t-t_{1 / 2}\right)\right)\right)
$$

where $t$ is the time post-ovariectomy, and $A, a$ and $t_{1 / 2}$ are parameters whose values were determined by best fit analysis using the equation fitting capabilities of SLIDEWRITE (Advanced Graphics Software, Inc., Incinitas, CA, USA). Equation 1 was chosen empirically because it provided the best fit to the data with a minimum number of parameters. $A$ is the minimum value approached by the sigmoidal curve, and reflects sucrose permeability after tight junction closure. The steepness of the transition, which describes the rate of decrease in blood sucrose level during closure, is determined by the term a. Tight junction closure time was defined as $t_{1 / 2}$, the mid-point of the sigmoidal curve. Closure times were averaged over all the animals in each experimental group and are given as means and standard errors. Significance of the differences between means obtained from different treatments were determined by Student's $t$-test.

\section{RIAs for corticosterone and prolactin}

Blood samples for corticosterone analysis were collected from the tail vein. The animals were gently restrained and the blood sample collected within $3 \mathrm{~min}$, so that the effect of handling stress on corticosterone serum level would be minimized. Serum was collected from blood samples centrifuged at $4{ }^{\circ} \mathrm{C}$, then stored at $-70{ }^{\circ} \mathrm{C}$ until RIA was performed. Serum samples were diluted 100-fold with distilled water, boiled for $5 \mathrm{~min}$, and extracted with six volumes of ether. The aqueous fractions of the samples were frozen to facilitate the collection of the ether fractions, which were then collected and evaporated under vacuum. The samples, along with corticosterone standards (Sigma), were analyzed for corticosterone with a RIA kit purchased from ICN (Bromedicals, Costa Mesa, CA, USA). Blood samples for prolactin assay were collected from the tail vein; after clotting they were centrifuged at $4{ }^{\circ} \mathrm{C}$. Serum was collected and stored at $-70{ }^{\circ} \mathrm{C}$ until prolactin assay was performed. The prolactin serum level was measured at the National Pituitary Hormone Center (Harbor-UCLA Medical Center, Torrance, CA, USA).

\section{Results}

\section{$\left[{ }^{14} \mathrm{C}\right]$ Sucrose passage from mammary lumen to blood during pregnancy and lactation}

To assess the permeability of the mouse mammary epithelium during pregnancy and lactation, a radiolabeled tracer, $\left[{ }^{14} \mathrm{C}\right]$ sucrose, was injected into the lumen of the mammary gland via the teat canal. In day 16-17 pregnant mice, $\left[{ }^{14} \mathrm{C}\right]$ sucrose was detected almost immediately in the bloodstream after its injection into the lumen (Fig. 1A). The level of $\left[{ }^{14} \mathrm{C}\right]$ sucrose peaked $5-10 \mathrm{~min}$ after injection, then declined exponentially with a half-time of $21 \mathrm{~min}$. In day 1 lactating mice, the level of $\left[{ }^{14} \mathrm{C}\right]$ sucrose in the bloodstream remained at background throughout the course of the experiment. As a check that the absence of $\left[{ }^{14} \mathrm{C}\right]$ sucrose in the bloodstream of the lactating mouse reflected the absence of leakage from the mammary gland into the bloodstream, the amount of $\left[{ }^{14} \mathrm{C}\right]$ sucrose remaining in the mammary gland was measured. One hour after 


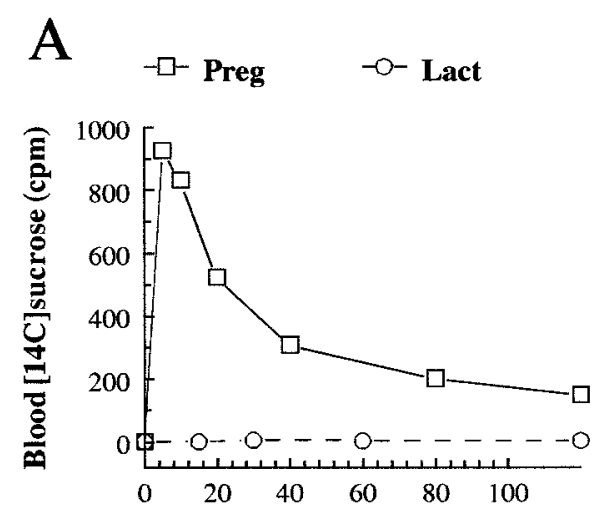

B

Post-injection Time (minutes)
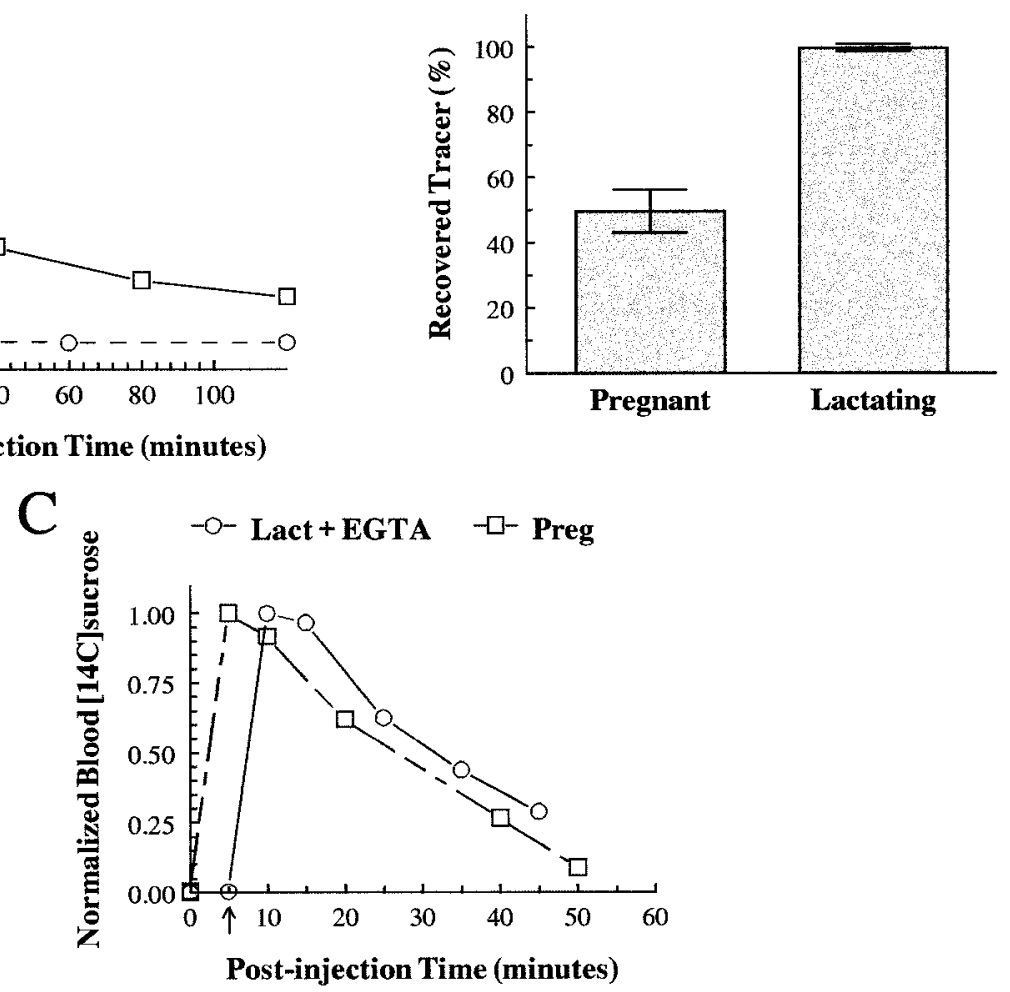

\begin{abstract}
Figure $1\left[{ }^{14} \mathrm{C}\right]$ sucrose as a tracer for the paracellular permeability of the mammary epithelium. (A) $\left[{ }^{14} \mathrm{C}\right]$ sucrose in the bloodstream after injection into the lumen of the mammary gland of pregnant $(\square)$ and lactating $(\bigcirc)$ mice. In the pregnant mouse, the $\left[{ }^{14} \mathrm{C}\right]$ sucrose counts in the blood rapidly increased, then declined exponentially with a $t_{1 / 2}$ of $21.3 \mathrm{~min}$. In the lactating mouse, $\left[{ }^{14} \mathrm{C}\right]$ sucrose counts remained at the background level. (B) Recovery of $\left[{ }^{14} \mathrm{C}\right]$ sucrose from pregnant and lactating glands $1 \mathrm{~h}$ after injection of tracer. Shown are means and S.E.M. from three separate experiments. (C) Effect of EGTA on appearance of counts in the bloodstream $(\bigcirc)$. At arrow, $8 \mu \mathrm{l}$ of $5 \mathrm{mM}$ EGTA were injected intraductally. Data from an experiment in a pregnant mouse are shown for comparison ( $\square$ ).
\end{abstract}

injection, the mammary gland was excised, homogenized, and the content of $\left[{ }^{14} \mathrm{C}\right]$ sucrose determined. In pregnant mice, only $49 \cdot 5 \pm 6 \cdot 6 \%$ of the injected $\left[{ }^{14} \mathrm{C}\right]$ sucrose remained in the mouse mammary gland $1 \mathrm{~h}$ after injection, whereas in lactating mice, $99 \cdot 8 \pm 1 \cdot 0 \%$ of the injected dose was recovered (Fig. 1B).

EGTA injection has been shown to open mammary tight junctions in the lactating goat (Neville \& Peaker 1981). If the tight junctions block the passage of $\left[{ }^{14} \mathrm{C}\right] \mathrm{su}-$ crose into the bloodstream of the lactating animal, then opening the tight junctions with EGTA should allow passage of the tracer. To test this hypothesis, an isosmotic solution of sucrose containing $5 \mathrm{mM}$ EGTA was injected intraductally into the fourth mammary gland of a day 1 lactating mouse $5 \mathrm{~min}$ after an intraductal injection of $\left[{ }^{14} \mathrm{C}\right]$ sucrose. Prior to the EGTA injection, the $\left[{ }^{14} \mathrm{C}\right] \mathrm{su}-$ crose in the bloodstream remained, as expected, at the background level (Fig. 1C). Immediately after the EGTA injection, the blood level of $\left[{ }^{14} \mathrm{C}\right]$ sucrose increased rapidly, peaking at $5 \mathrm{~min}$, then declined with a time course nearly identical to that observed in the pregnant animal. The results of this experiment provide additional evidence that the absence of lumen to blood $\left[{ }^{14} \mathrm{C}\right]$ sucrose leakage during lactation was not due to dilution by milk and that the tight junctions serve as a barrier to solute passage during lactation.

Finally, to examine the pathway of $\left[{ }^{14} \mathrm{C}\right]$ sucrose leakage across the mammary epithelium, FITC-albumin was injected intraductally into the mammary glands of pregnant and lactating mice, followed within $5 \mathrm{~min}$ by fixative. The gland was sectioned and the sections viewed with a fluorescent microscope. During lactation (Fig. 2B), FITCalbumin was confined to the alveolar lumina. During pregnancy, the tracer was detected at high intensity in the lumen, but also in the paracellular spaces and the interstitial space (Fig. 2A). To rule out passage of tracer through 


\section{Pregnant}

Lactating

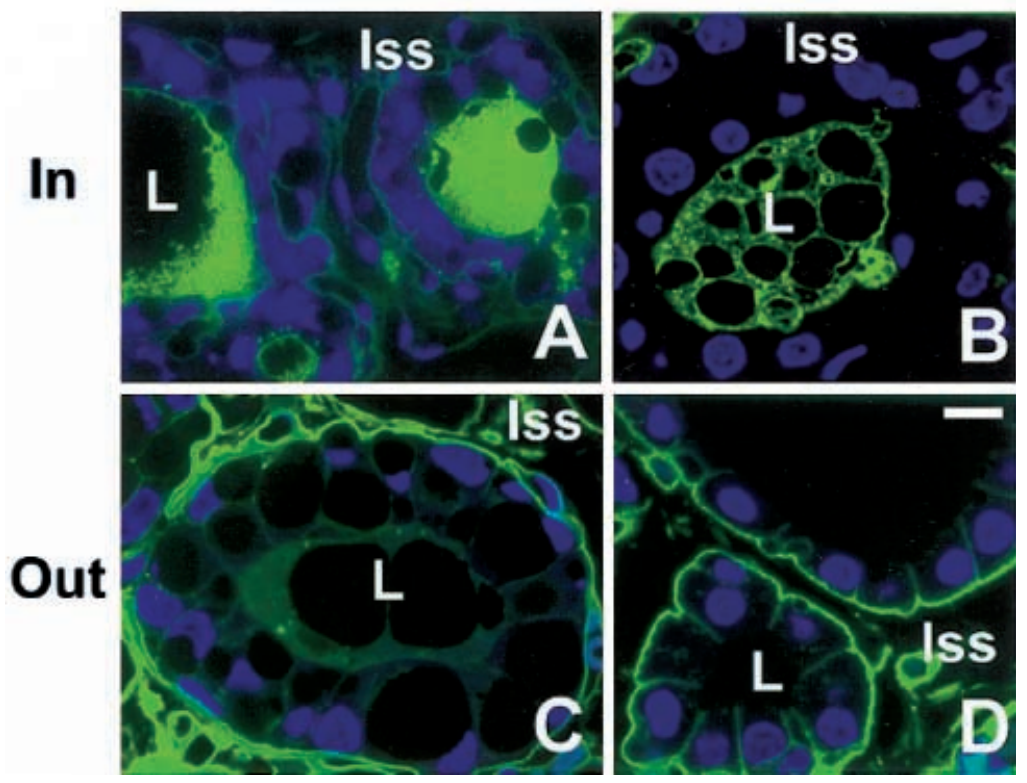

Figure 2 FITC-albumin as a tracer for tight junction permeability. (A) and (C) Pregnant mice. (B) and (D) Lactating mice. (A) and (B) Tracer was injected intraductally (designated ' $I n$ ' on the figure) followed within 5 min with fixative and the glands excised, fixed, embedded in plastic, sectioned and visualized with the fluorescent microscope. In the gland of pregnancy, tracer can be seen in the lumen (L) and the interstitial space (Iss); in lactation it is confined to the lumen. The intensity of stain in the interstitial spaces should be compared in these photographs. (C) and (D) The in situ gland was incubated with tracer for $1 \mathrm{~h}$ to expose the basolateral surface of the alveoli (designated 'Out') as described in Materials and Methods, the gland excised, fixed and sectioned as before. In pregnancy, tracer can be seen through the interstitial space and in the lumen; during lactation tracer is confined to the interstitial and basolateral spaces. In these photographs the intensity of fluorescence should be compared in the lumina. Nuclei in these sections were stained with DAPI and are blue in the figure. The magnification bar in (D) represents $10 \mu \mathrm{m}$ and applies to all panels. the cells, we compared the intensity of background fluorescence in cells from alveoli with dye in the lumen to background fluorescence in cells in alveoli containing no dye. There was no significant difference, indicating that the injected fluorescent tracer was not taken up by the mammary epithelial cells of the pregnant mouse. In addition when a solution containing FITC-albumin was layered on the exposed mammary gland of an anesthetized mouse and allowed to remain for $1 \mathrm{~h}$ (Monks et al. 2001), dye appeared in the lumina of exposed alveoli in the pregnant mouse (Fig. 2C). In the lactating mouse, tracer can be seen extending up the paracellular spaces but it stops at the apical border of the cells (Fig. 2D).

The results of all these experiments validate the use of intraductal injection of $\left[{ }^{14} \mathrm{C}\right]$ sucrose to measure tight junction permeability in the in vivo mammary gland and support the conclusion reached more than two decades ago by Linzell \& Peaker $(1971,1974)$ and Pitelka et al. (1973) that the tight junctions of the mammary epithelium are permeable during pregnancy and tightly closed during lactation. Having developed an in vivo assay system for the functional state of the tight junctions in the mouse, we went on to define the time course of the permeability change and the hormonal changes responsible during stage 2 lactogenesis.

Effects of ovariectomy on tight junction permeability in late pregnant mice

Bilateral ovariectomy was performed on 17 day pregnant mice to remove the source of ovarian hormones. Changes in tight junction permeability were monitored by periodic injection of $\left[{ }^{14} \mathrm{C}\right]$ sucrose into the lumen of the mammary gland as described in Materials and Methods. The level of $\left[{ }^{14} \mathrm{C}\right]$ sucrose in the blood $5 \mathrm{~min}$ after each injection was recorded at intervals after ovariectomy to give a measure of $\left[{ }^{14} \mathrm{C}\right]$ sucrose leakage across the mammary epithelium. As 

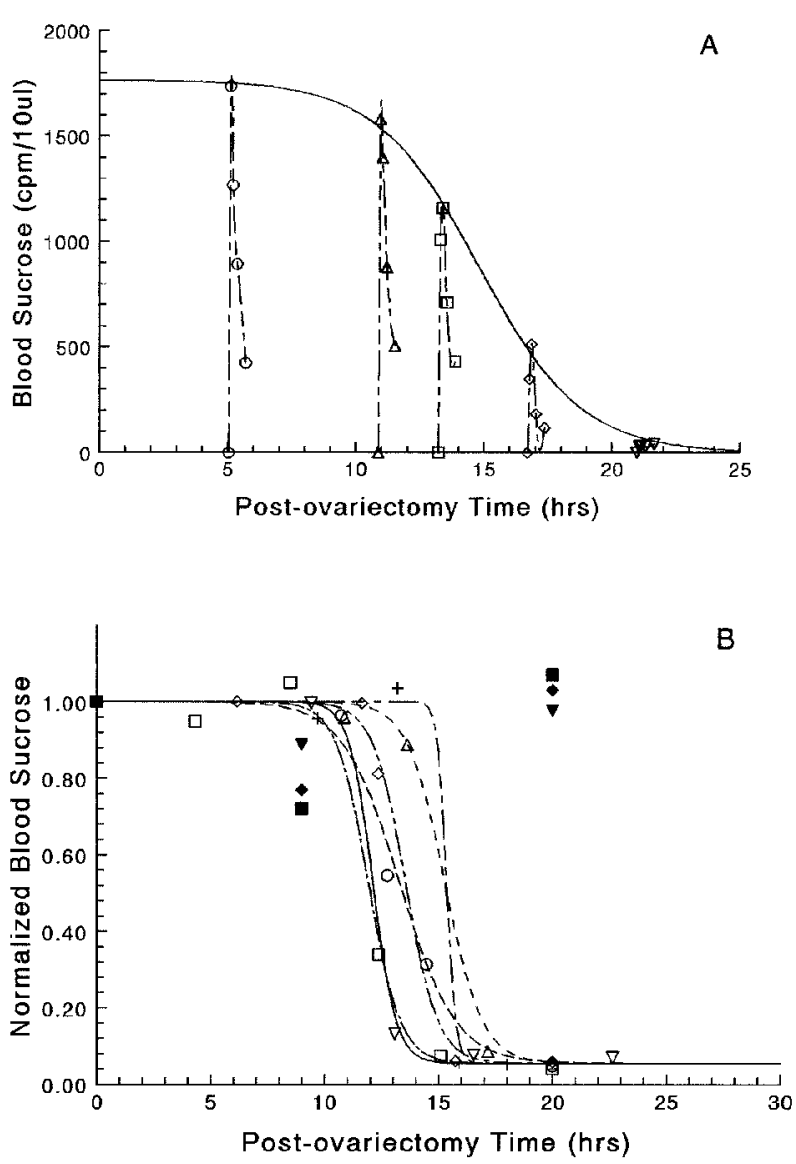

Figure 3 Tight junction closure in late pregnant mice induced by bilateral ovariectomy. (A) $\left[{ }^{14} \mathrm{C}\right]$ Sucrose was injected into the lumen of the mammary gland at various intervals after ovariectomy and the counts in the blood monitored for the subsequent 40 min (dashed curves). The heavy curve is the best fit to equation 1; numerically, $y=1765 /(1+\exp (0 \cdot 5(x-14 \cdot 82)))$. Each dashed curve under the heavy black line $(O, \triangle, \square, \nabla, \diamond)$ shows the

$\left[{ }^{14} \mathrm{C}\right]$ sucrose level after single injection. (B) Time course of tight junction closure in six ovariectomized mice. Open symbols show the height of the $\left[{ }^{14} \mathrm{C}\right]$ sucrose curve measured 5 min after injection, normalized to the pre-ovariectomy level. Each different symbol shows data from an individual mouse. The curves represent the best fit to equation 1 . The solid symbols $(\boldsymbol{\nabla}, \bullet$ represent data from three sham-ovariectomized mice.

seen in Fig. 3A, the $\left[{ }^{14} \mathrm{C}\right]$ sucrose peak remained at the pre-ovariectomy level for about $10 \mathrm{~h}$, declining to background levels by $20 \mathrm{~h}$.

The time course of tight junction closure was highly consistent among the six ovariectomized mice as shown by the data in Fig. 3B. Using the midpoints of the sigmoidal curves as the times of tight junction closure, an average value of $13.6 \pm 1.5$ (s.E.M.) h was obtained from these six mice (see also Table 1, Exp. 2). Three pregnant mice were subjected to sham ovariectomy to rule out the possibility that other factors associated with the surgical procedure, such as a potential stress-induced increase in glucocorticoid, were responsible for tight junction closure. The $\left[{ }^{14} \mathrm{C}\right]$ sucrose concentration in the blood remained at the control level for $20 \mathrm{~h}$ after sham ovariectomy, when the experiment was terminated (Fig. 3B and Table 1, Exp. 1).

Effects of exogenous progesterone on ovariectomy-induced tight junction closure

If progesterone withdrawal is the trigger for tight junction closure in the late pregnant mouse, then exogenous progesterone should inhibit the effect of ovariectomy. Since progesterone is metabolized by the body, the inhibition should be only temporary. To test this hypothesis, day 17 pregnant mice were ovariectomized and, $1.5 \mathrm{~h}$ after surgery, injected with progesterone. The permeability of the mammary epithelium was monitored with $\left[{ }^{14} \mathrm{C}\right] \mathrm{su}-$ crose as before. The mean tight junction closure time was $20 \cdot 4 \pm 1 \cdot 4 \mathrm{~h}$ (Table 1, Exp. 3), representing a highly significant delay in closure. The length of the delay depended on the time and dose of the progesterone injection. A single injection given immediately after ovariectomy resulted in a delay of $4.4 \mathrm{~h}$, compared with the mean delay of $6.8 \mathrm{~h}$ with the single injection given $1.5 \mathrm{~h}$ after ovariectomy. Two injections, one given immediately after ovariectomy and the other $3 \mathrm{~h}$ after ovariectomy, increased tight junction closure delay by $9 \cdot 3 \mathrm{~h}$ (data not shown). These data provide strong evidence that withdrawal of progesterone is the cause of the ovariectomy-induced tight junction closure rather than other hormonal changes associated with either surgery or ovariectomy.

A single injection of progesterone was always effective in increasing tight junction closure delay when given up to $4 \mathrm{~h}$ after ovariectomy. However, at $6 \mathrm{~h}$ after ovariectomy, a single injection failed to alter the timing of tight junction closure in one of two experiments. Injections given at $8 \mathrm{~h}$ post-ovariectomy did not affect tight junction closure time at all. These observations suggest that commitment to tight junction closure occurs between 4 and $8 \mathrm{~h}$ post-ovariectomy.

\section{Effects of RU486 on tight junction permeability in late pregnant mice}

If the withdrawal of progesterone is the trigger for tight junction closure in the mammary gland after ovariectomy of the late pregnant mouse, RU486, a progesterone antagonist (Truss et al. 1994, Cadepond et al. 1997), should also trigger tight junction closure. When injected into day 17 pregnant mice, the drug induced tight junction closure in the mammary epithelium with an average half-time of $10 \cdot 4 \pm 0 \cdot 6 \mathrm{~h}$ (Table 1, Exp. 4), $3 \cdot 2 \mathrm{~h}$ earlier than ovariectomy. The difference is likely due to the time necessary to metabolize endogenous progesterone after ovariectomy, and is significant $(P<0 \cdot 01, t$-test $)$. These results provide 
Table 1 Effects of endocrine maneuvers on time of tight junction closure. Day 17 pregnant mice were subjected to sham ovariectomy or ovariectomy plus the other treatments as indicated in column 2. Tight junction permeability was measured by intraductal injection of $\left[{ }^{14} \mathrm{C}\right]$ sucrose at intervals over $20 \mathrm{~h}$, when the experiment was terminated. Tight junction closure time was defined as $t_{1 / 2}$ in equation 1 and given as means \pm S.E.M. in column 6

\section{Effect on}

Treatment

Exp.

1

2

3

3 OVEX+Progesterone

(0.028 mg/g $1.5 \mathrm{~h}$ after OVEX)

$4 \quad$ RU486 $(0.01 \mathrm{mg} / \mathrm{g})$

5 DEX $(0.01 \mathrm{mg} / \mathrm{g}, n=3$; and $0.02 \mathrm{mg} / \mathrm{g}, n=3$ )

6 OVEX+ADEX

7 OVEX+HYSTEX

8

9

10

11

Remove

Inhibited

$-$

Remove

Remove

Remove

Remove

OVEX+ADEX+HYSTEX+ DEX $(0.01 \mathrm{mg} / \mathrm{g})$

$\mathrm{OVEX}+\mathrm{BrCr}$

OVEX+ADEX+HYSTEX+
Remove

Remove
Progesterone

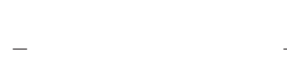

Remove with delay $\operatorname{DEX}(0 \cdot 01 \mathrm{mg} / \mathrm{g})+\operatorname{BrCr}(0 \cdot 005 \mathrm{mg} / \mathrm{g})$

\section{Corticosteroid}

-

$-$

- (possibly decreased)

Increased

Decrease

Decrease

Remove

Remove and add back

$-$

Remove and add back

\section{Prolactin and $\mathrm{mPL}$}

$-$

$-$

$-$

$-$

$-$

No change PRL Remove $\mathrm{mPL}$

No change PRL Remove $\mathrm{mPL}$

No change PRL Remove $\mathrm{mPL}$

Decrease PRL No change $\mathrm{mPL}$

Decrease PRL Remove $\mathrm{mPL}$
Tight junction closure time $n$

No closure 3

$13 \cdot 6 \pm 1 \cdot 5 \quad 6$

$20 \cdot 4 \pm 1 \cdot 4^{*} \quad 3$

$10 \cdot 4 \pm 0 \cdot 6^{*} \quad 4$

No closure 6

$13 \cdot 1 \pm 1 \cdot 6 \quad 4$

No closure 3

No closure 3

$12 \cdot 8 \pm 1 \cdot 6 \quad 3$

$11 \cdot 8 \pm 1 \cdot 0 \quad 5$

No closure $\quad 3$

Abbreviations: OVEX, ovariectomy; ADEX, adrenalectomy; HYSTEX, hysterectomy; DEX, dexamethasone; BrCr, bromocryptine; PRL, prolactin; mPL, mouse placental lactogen; -, no effect.

*Significantly different from OVEX alone; $P<0 \cdot 01$ (Student's $t$-test).

additional support for the conclusion that progesterone withdrawal is the trigger for tight junction closure during stage 2 lactogenesis.

\section{Role of glucocorticoid in epithelial permeability during the transition from pregnancy to lactation}

To determine whether an increase in the level of glucocorticoid can induce tight junction closure in late pregnant mice, dexamethasone, a powerful synthetic glucocorticoid, was injected into day 17 pregnant mice at doses of $10 \mu \mathrm{g} / \mathrm{g}$ and $20 \mu \mathrm{g} / \mathrm{g}$ of body weight. Tight junction permeability was monitored with $\left[{ }^{14} \mathrm{C}\right]$ sucrose as before. In six experiments, dexamethasone treatment did not induce tight junction closure in $20 \mathrm{~h}$ (Table 1, Exp. 5) although, if abortion of the fetuses ensued, tight junction closure was observed at later times. Bilateral adrenalectomy, which removes the source of maternal glucocorticoid, did not affect the time course of tight junction closure in ovariectomized mice (Table 1, Exp. 6). These results indicate that high levels of glucocorticoid neither produce nor are required for tight junction closure and provide strong evidence that the rise in glucocorticoid levels observed at parturition in many species is not the trigger for closure.
That ablation of the maternal adrenals does not remove all glucocorticoid from pregnant mice is clear from the results of RIA of serum corticosterone, the main glucocorticoid in mice, in day 17 pregnant animals after ovariectomy, after ovariectomy plus adrenalectomy, or after ovariectomy plus adrenalectomy and hysterectomy (Fig. 4). In all three groups, the level of corticosterone was highest immediately after surgery, most likely due to surgical stress, then gradually declined. Adrenalectomy significantly reduced the corticosterone level compared with that of ovariectomy alone, but the level approached zero only after $15 \mathrm{~h}$. With both adrenalectomy and hysterectomy, which remove both maternal and fetal sources of glucocorticoid, corticosterone dropped rapidly, and disappeared almost completely after $4 \mathrm{~h}$. These results show that a significant portion of corticosterone in the maternal circulation comes from the fetuses, and that complete removal of glucocorticoid requires both adrenalectomy and hysterectomy.

When adrenalectomy and hysterectomy were performed at the time of ovariectomy, tight junction closure did not occur, suggesting that the presence of glucocorticoid is essential to this process (Table 1, Exp. 8). The observation that dexamethasone treatment restored closure 


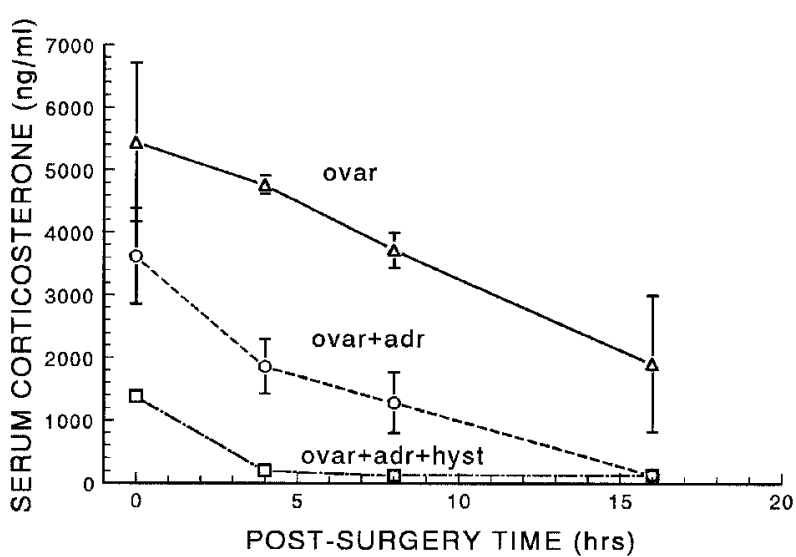

Figure 4 Serum corticosterone levels in day 17 pregnant mice subjected to ovariectomy alone $(\triangle)$, ovariectomy plus adrenalectomy $(\bigcirc)$, and ovariectomy plus adrenalectomy and hysterectomy $(\square)$. Serum samples were collected within 3 min after the animal was restrained to minimize glucocorticoid secretion in response to handling stress. The first sample was taken immediately after surgery while the animal was still anesthetized. Each treatment group consisted of three mice.

with the same time course is consistent with this conclusion (Table 1, Exp. 9). These results provide strong evidence that glucocorticoid is necessary for tight junction closure triggered by progesterone withdrawal.

Interestingly, hysterectomy along with ovariectomy was sufficient to prevent tight junction closure even through the measurements of corticosterone levels in the maternal circulation (e.g. the difference between lines ovar+adr and ovar+adr+hyst in Fig. 4) suggest that sufficient glucocorticoid should be present from the maternal adrenals to support closure (Table 1, Exp. 7). The interpretation of this finding, consistent in three mice, is unclear but may indicate a more complex interaction between the concentration of glucocorticoids and the concentrations of the lactogenic hormones prolactin and placental lactogen present in the periparturient mouse.

\section{Role of prolactin in tight junction closure}

To examine the effect of prolactin on tight junction closure, day 17 pregnant mice were given an injection of bromocryptine, $0.005 \mathrm{mg} / \mathrm{g}$ of body weight, at the time of ovariectomy to inhibit the secretion of prolactin. This treatment did not affect tight junction closure, which proceeded with a time course similar to that observed with ovariectomy alone (Table 1, Exp. 10). An RIA performed on serum samples collected from bromocryptine-treated and control ovariectomized mice showed that the level of serum prolactin was significantly decreased in response to bromocryptine, dropping to $39 \cdot 8 \%$ of control at $8 \mathrm{~h}$, then to $15.9 \%$ at $16 \mathrm{~h}$. These results suggest that this dose of bromocryptine is effective in inhibiting prolactin secretion, and that pituitary prolactin is not essential for tight junction closure.
The possibility that placental lactogen was activating prolactin receptors in the mammary gland during tight junction closure was investigated by subjecting day 17 pregnant mice to ovariectomy, adrenalectomy and hysterectomy, and treatment with bromocryptine to inhibit prolactin secretion and dexamethasone to replace the lost glucocorticoid. This treatment prevented tight junction closure (Table 1, Exp. 11). When this experiment is compared with the same treatment without bromocryptine (Exp. 9), where the mean closure time was $12 \cdot 8 \pm 1.6 \mathrm{~h}$, it becomes clear that activation of the prolactin receptor is required for tight junction closure. However, the presence of either prolactin from the maternal pituitary or placental lactogen appears to be sufficient.

\section{Discussion}

Tight junction permeability is closely linked with milk secretion under many conditions (Linzell et al. 1975, Stelwagen et al. 1997, Allen 1990) and tight junction closure around parturition plays an important role in lactation by preventing the loss of milk components from the lumen of the mammary gland. There is substantial evidence that progesterone withdrawal is the main trigger for lactogenesis (Kuhn 1969, Deis \& Delouis 1983, Nishikawa et al. 1994, Neville et al. 2001). Our observation that progesterone withdrawal produced by the surgical removal of the ovaries led to tight junction closure is consistent with the hypothesis that tight junction closure is regulated by the same hormones.

Ovariectomy also produces estrogen withdrawal, which could directly or indirectly, by down-regulating progesterone receptors, affect tight junction permeability (Haslam \& Shyamala 1979, Fendrick et al. 1998). However, the findings that exogenous progesterone delayed tight junction closure and that RU486 produced closure in the absence of ovariectomy suggest that estrogen is not a major player in the process. As expected, progesterone withdrawal also triggered parturition; however, parturition itself did not appear to be the direct cause of tight junction closure, since the timing of parturition was erratic, usually occurred after closure, and showed no correlation to the relatively consistent time course of tight junction closure.

The pathway by which progesterone acts to prevent lactogenesis is far from clear. Progesterone receptors are present at a low level in the mouse mammary gland at late pregnancy (Haslam \& Shyamala 1980, Shyamala et al. 1990). A possible mechanism for the inhibitory effect of progesterone on tight junction closure could be competitive inhibition of the binding of glucocorticoid to its receptor (Ganguly et al. 1982). However, RU486, an antagonist that blocks the actions of both progesterone and glucocorticoid at their receptors (Truss et al. 1994, Cadepond et al. 1997), induced tight junction closure in 
late pregnant mice. If progesterone withdrawal acted through the glucocorticoid receptor, RU486 would be expected to inhibit tight junction closure, rather than promoting it as observed in these experiments. Second, a high dose of dexamethasone, a powerful synthetic glucocorticoid that should displace progesterone and activate glucocorticoid receptors, did not induce tight junction closure in day 16 pregnant mice. Further, the inhibitory action of RU 486 suggests that classical progesterone receptors are involved rather than some other reported site of progesterone binding such as the oxytocin receptor (Grazzini et al. 1998). However, the detailed mechanism involved requires additional investigation.

Nonetheless, it seemed unlikely that progesterone is the only important hormone in the regulation of mammary tight junction permeability, considering the substantial body of evidence demonstrating that glucocorticoids and prolactin are necessary for lactation (Neville et al. 2001). Further, Thompson (1996) showed that local injection of cortisol into the mammary gland of the late pregnant goat produced a decrease in the sodium, and an increase in the potassium concentration of the mammary secretion product. Using mammary cell cultures on Transwell filters, Firestone and his colleagues (Zettl et al. 1992, Woo et al. 1999) found that dexamethasone, a powerful glucocorticoid, induced a decrease in tight junction permeability in two different cell types, as measured by transepithelial electrical resistance. In the present study, we found that the presence of some glucocorticoid was also essential for tight junction closure, since the removal of both maternal and fetal sources of glucocorticoid by a combination of adrenalectomy and hysterectomy prevented tight junction closure, and glucocorticoid replacement restored the closure event in these mice. It is of interest that Feng et al. (1995), studying the effects of acute removal of the pups during full lactation, found that both progesterone and deoxycorticosterone inhibited apoptosis. Whether glucocorticoids are acting to prevent apoptosis in the context of lactogenesis, stage 2, or whether they promote tight junction closure by a more direct action as implied by the in vitro studies of Firestone and colleagues remains to be determined. Recent studies in this laboratory using TUNEL assays reveal minimal apoptosis in the mammary glands of late pregnant mice, ruling out cell loss as the cause of epithelial permeability at this reproductive stage (J McManaman \& M C Neville, unpublished observation).

Prolactin has also been associated with the regulation of tight junctions in the mammary epithelium. In the present study, we showed that ovariectomy-induced tight junction closure can proceed when prolactin secretion is inhibited by bromocryptine. When the source of placental lactogen was removed by hysterectomy, and dexamethasone was given to replace fetal glucocorticoid, tight junction closure also proceeded normally. Therefore, neither placental lactogen nor a high level of prolactin was necessary for tight junction closure to occur. However, a combination of bromocryptine to inhibit prolactin secretion and hysterectomy to remove placental lactogen prevented tight junction closure. These results indicate that some activity from prolactin receptors is necessary for tight junction closure, and it appears that the presence of either prolactin or placental lactogen alone is sufficient.

The effect of prolactin on tight junction permeability may be secondary to its effect on the maintenance of the mammary epithelium. Linzell et al. (1975), studying the rabbit, found that treatment with prolactin reversed a decline in milk yield and an increase in milk sodium observed in late lactation. When $\left[{ }^{14} \mathrm{C}\right]$ sucrose was infused into the bloodstream of late lactating rabbits, prolactin significantly reduced the rate of $\left[{ }^{14} \mathrm{C}\right]$ sucrose entry from the bloodstream into milk, confirming that the changes in milk composition reflected changes in paracellular permeability. Flint \& Gardner (1994) inhibited prolactin secretion with bromocryptine and observed reduced milk secretion and increased mammary epithelial permeability in the lactating rat as indicated by an increase in milk sodium level. These changes were accompanied by increased cell loss, as shown by a decrease in the DNA content of the rat mammary gland. Travers et al. (1996) also showed that prolactin withdrawal leads to apoptosis. All these results suggest that the role of prolactin might be to maintain the integrity of the mammary epithelium by preventing apoptosis, with secondary effects on epithelial permeability. Nevertheless, a direct effect of prolactin on mammary epithelial tight junction permeability can not at present be ruled out.

The mechanism for tight junction closure itself is not completely understood, but appears to correlate with certain ultrastructural changes in the tight junction network. Thus Pitelka et al. (1973), using freeze fracture electron microscopy, found that the tight junction network of the mouse mammary epithelium was quite disorganized during pregnancy with fewer interconnections, more loose ends, and fewer tight junctional strands between the lumen and the basolateral space than the orderly tight junction network of the lactating mammary gland. We have repeated these experiments and found that the change in tight junction permeability during the transition from pregnancy to lactation can be accounted for by organization of tight junction strands (D-A Nguyen \& M C Neville, unpublished observations).

In conclusion, results from this study provide strong evidence that progesterone withdrawal is the trigger for tight junction closure in the mouse mammary epithelium during the transition from pregnancy to lactation. Once progesterone inhibition is lifted, however, glucocorticoid and prolactin are required for the process to proceed. The consistency of the time course with which tight junction closure occurs in response to progesterone withdrawal suggests that the process involves a highly ordered sequence of steps, examination of which could yield 
valuable insight into the regulation of both tight junction permeability and progesterone action.

\section{Acknowledgements}

Preparation of this article was supported in part by NIH Grant no. R37-HD19547. The authors thank Steve Nordeen, Dean Edwards and Bruce Wallace for their many helpful discussions during the course of this research.

\section{References}

Allen JC 1990 Milk synthesis and secretion rates in cows with milk composition changed by oxytocin. Journal of Dairy Science $\mathbf{7 3}$ 975-984.

Berga SE 1984 Electrical potentials and cell-to-cell dye movement in mouse mammary gland during lactation. American Journal of Physiology 247 C20-C25.

Cadepond FA, Ulmann A \& Baulieu EE 1997 RU486 (mifepristone): mechanisms of action and clinical uses. Annual Review of Medicine 48 129-156.

Deis RP \& Delouis C 1983 Lactogenesis induced by ovariectomy in pregnant rats and its regulation by oestrogen and progesterone. Journal of Steroid Biochemistry 18 687-690.

Fendrick JL, Raafat AM \& Haslam SZ 1998 Mammary gland growth and development from the postnatal period to post-menopause: ovarian steroid receptor ontogeny and regulation in the mouse. Journal of Mammary Gland Biology and Neoplasia 3 7-22.

Feng ZW, Marti A, Jehn B, Altermatt HJ, Chicaiza G \& Jaggi R 1995 Glucocorticoid and progesterone inhibit involution and programmed cell death in the mouse mammary gland. Journal of Cell Biology 131 1095-1103.

Fleet IR, Goode JA, Hamon MH, Laurie MS, Linzell JL \& Peaker M 1975 Secretory activity of goat mammary glands during pregnancy and the onset of lactation. Journal of Physiology 251 763-773.

Flint DJ \& Gardner M 1994 Evidence that growth hormone stimulates milk synthesis by direct action on the mammary gland and that prolactin exerts effects on milk secretion by maintenance of mammary deoxyribonucleic acid content and tight junction status. Endocrinology 135 1119-1124.

Ganguly R, Majumder PK, Ganguly N \& Banerjee MR 1982 The mechanism of progesterone-glucocorticoid interaction in regulation of casein gene expression. Journal of Biological Chemistry 257 2182-2187.

Grazzini E, Guillon G, Mouillac B \& Zingg HH 1998 Inhibition of oxytocin receptor function by direct binding of progesterone. Nature 392 509-512.

Haslam SZ \& Shyamala G 1979 Progesterone receptors in normal mammary glands of mice: characterization and relationship to development. Endocrinology 105 786-795.

Haslam SZ \& Shyamala G 1980 Progesterone receptors in normal mammary gland: receptor modulations in relation to differentiation. Journal of Cell Biology 86 730-737.

Kuhn NJ 1969 Progesterone withdrawal as the lactogenic trigger in the rat. Journal of Endocrinology 44 39-54.

Linzell JL \& Peaker M 1971 The permeability of mammary ducts. Journal of Physiology 216 701-716.
Linzell JL \& Peaker M 1974 Changes in colostrum composition and in the permeability of the mammary epithelium at about the time of parturition in the goat. Journal of Physiology 243 129-151.

Linzell JL, Peaker M \& Taylor JC 1975 The effects of prolactin on milk secretion and on the permeability of the mammary epithelium in the rabbit. Journal of Physiology 253 547-563.

Monks J, Hanson L, Huey P, Eckel RH \& Neville MC 2001 A lipoprotein particle in mouse milk. Journal of Lipid Research 42 1-11.

Neville MC 1995 Lactogenesis in women: a cascade of events revealed by milk composition. In The Composition of Milks, pp 87-98. Ed. RD Jensen. San Diego: Academic Press.

Neville MC \& Peaker M 1981 Ionized calcium in milk and the integrity of the mammary epithelium in the goat. Journal of Physiology 313 561-570.

Neville MC, Morton JA \& Umemora S 2001 Lactogenesis: the transition between pregnancy and lactation. Pediatric Clinics of North America 48 35-52.

Nguyen DAD, Beeman NG, Lewis MT, Schaack J \& Neville MC 2000 Intraductal injection into the mouse mammary gland. In Methods in Mammary Gland Biology and Breast Cancer Research, pp 259-270. Eds MM Ip \& BB Asch. New York: Kluwer Academic/Plenum.

Nishikawa S, Moore RC, Nonomura N \& Oka T 1994 Progesterone and EGF inhibit mouse mammary gland prolactin receptor and $\beta$-casein gene expression. American Journal of Physiology 267 C1467-C1472.

Pitelka DR, Hamamoto ST, Duafala JG \& Nemanic MK 1973 Cell contacts in the mouse mammary gland. I. Normal gland in postnatal development and the secretory cycle. Journal of Cell Biology $\mathbf{5 6}$ 797-818.

Shyamala G, Schneider W \& Schott D 1990 Developmental regulation of murine mammary progesterone receptor gene expression. Endocrinology 126 2882-2889.

Stelwagen K, Farr VC, McFadden HA, Prosser CG \& Davis SR 1997 Time course of milk accumulation-induced opening of mammary tight junctions, and blood clearance of milk components. American Journal of Physiology 273 R379-R386.

Thompson GE 1996 Cortisol and regulation of tight junctions in the mammary gland of the late-pregnant goat. Journal of Dairy Research 63 305-308.

Travers MT, Barber E, Tonner E, Quarrie L, Wilde CJ \& Flint DJ 1996 The role of prolactin and growth hormone in the regulation of casein gene expression and mammary cell survival: relationships to milk synthesis and secretion. Endocrinology 137 1530-1539.

Truss M, Bartsch J \& Beato M 1994 Antiprogestins prevent progesterone receptor binding to hormone responsive elements in vivo. PNAS 91 11333-11337.

Woo PL, Chung D, Guan Y \& Firestone GL 1999 Requirement for Ras and PI 3-kinase signaling uncouples the glucocorticoid-induced junctional organization and transepithelial electrical resistance in mammary tumor cells. Journal of Biological Chemistry 274 32818-32828.

Zettl KS, Sjaastad MD, Riskin PM, Parry G, Machen TE \& Firestone GL 1992 Glucocorticoid-induced formation of tight junctions in mouse mammary epithelial cells in vitro. PNAS 89 9069-9073.

Received in final form 22 February 2001

Accepted 14 April 2001 